\title{
Successful Neuropsychological Rehabilitation in a Patient With Cerebellar Cognitive Affective Syndrome
}

\author{
N. Ruffieux and F. Colombo \\ Unit of Neuropsychology and Aphasiology, Fribourg Hospital, Fribourg, Switzerland \\ E. Gentaz \\ Faculty of Psychology and Educational Sciences, Geneva University, Geneva, Switzerland
}

\author{
J.-M. Annoni
}

Unit of Neurology, Fribourg Hospital, Fribourg, Switzerland and Neurorehabilitation Service, Fribourg Hospital, Fribourg, Switzerland and Laboratory for Cognitive and Neurological Sciences, Department of Medicine, University of Fribourg, Fribourg, Switzerland

L. Chouiter and S. Roulin Hefti

Unit of Neuropsychology and Aphasiology, Fribourg Hospital, Fribourg, Switzerland

A. Ruffieux

Unit of Neurology, Fribourg Hospital, Fribourg, Switzerland

T. Bihl

Neurorehabilitation Service, Fribourg Hospital, Fribourg, Switzerland

\begin{abstract}
The objective of this case study was to describe the neuropsychological rehabilitation of a 16-year-old patient who presented a Cerebellar Cognitive Affective Syndrome (CCAS) following a bilateral cerebellar hemorrhage. The patient presented severe and diffuse cognitive deficits, massive behavioral disorders, and emotion regulation difficulties. The cognitive rehabilitation was performed in the chronic phase (one year after the onset of the hemorrhage) using a transdisciplinary neurobehavioral approach based on the patient's favorite interest (soccer). A significant behavioral and cognitive improvement was observed. The patient became progressively independent in all activities of daily living and was discharged home. The Functional Independence Measure at discharge was $124 / 126$ (vs. $37 / 126$ at entry). The patient was able to complete his schooling despite the mild cognitive and behavioral sequelae. This first description of the use of neurobehavioral therapy in a case of chronic CCAS suggests that (a) major clinical improvement can occur more than one year after the onset of the CCAS, showing the importance of long-term and intensive neurorehabilitation; and (b) when the cerebellum cannot properly play its regulator role in cognition, neuropsychological intervention through a behavioral and cognitive approach can be of great help by acting as an external modulator to help the patient regain control over himself.
\end{abstract}

Address correspondence to Nicolas Ruffieux, Department of Psychology, I(eye) and Brain Mapping Laboratory, Fribourg University, Rue P.-A.-de-Faucigny 2, 1701 Fribourg, Switzerland. E-mail: nicolas.ruffieux@unifr.ch 


\section{Key words: cerebellar cognitive affective syndrome, emulation board, executive functions, neurobehavioral approach, neuropsychological rehabilitation}

\section{INTRODUCTION}

In the nineteenth century, according to Franz Joseph Gall, the cerebellum was the anatomical localization of love (Spurzheim, 1815). During the first half of the twentieth century, Holmes (1939) conclusively established the involvement of the cerebellum in motor coordination. For a long period of time, the scientific community considered the cerebellum to have an exclusive motor function. It is only recently that neuroanatomical and clinical evidence suggested that the cerebellum also plays an important role in cognitive function (in particular, Botez, Gravel, Attig, \& Vezina, 1985; Leiner, Leiner, \& Dow, 1986; Schmahmann, 1991).

Schmahmann and Sherman (1998) further clarified the nonmotor role of the cerebellum, describing the cerebellar cognitive affective syndrome (CCAS). CCAS implies an impairment of executive functions, spatial cognition and language, emotional blunting, and personality changes. The syndrome is particularly associated with posterior and vermian cerebellar lesions. The clinical presentation of the syndrome is more severe in patients suffering from bilateral or diffuse cerebellar lesions. The authors put forward the hypothesis of "Dysmetria of Thought" to explain the common nature of impairment: the cerebellum modulates behavior, maintaining it around a homeostatic baseline that is appropriate to context. Moreover, they used this term in analogy with the motor system to describe impairments of higher-order behavior according to context. These deficits are related to the disruption of neural circuits linking prefrontal, temporal, posterior parietal, and limbic cortices with the cerebellum (Schmahmann, 2010).

In the last two decades, many studies have progressively demonstrated the range of cognitive deficits associated with cerebellar dysfunction, including linguistic processing (Klein, Milner, Zatorre, Meyer, \& Evans, 1995), verbal fluency (Richter et al., 2005; Peterburs, Bellebaum, Koch, Schwarz, \& Daum, 2010), visuospatial functions (Molinari, Petrosini, Misciagna, \& Leggio, 2004; Neau, Arroyo-Anllo, Bonnaud, Ingrand, \& Gil, 2000), procedural learning (Shin and Ivry, 2003); verbal memory (Grasby et al., 1993), executive functions (Bellebaum and Daum, 2007; Gottwald, Wilde, Mihajlovic, \& Mehdorn, 2004), attention (Gottwald, Mihajlovic, Wilde, \& Mehdorn, 2003), working memory (Chiricozzi, Clausi, Molinari, \& Leggio, 2008), sequencing (Leggio et al., 2008; Tedesco et al., 2011), and emotion (Schmahmann \& Sherman, 1998; Turner et al., 2007). In a large group of patients with focal cerebellar damage $(N=156)$, Tedesco et al. (2011) found that among the various cognitive domains, the ability to sequence was most severely affected.

Diverse functional neuroimaging studies have reported activations in the cerebellum during simple and complex cognitive tasks (e.g., Baillieux, De Smet, Paquier, De Deyn, \& Marien, 2008; Stoodley, 2012). Furthermore, supplementary evidence indicating a nonmotor role in the cerebellum has arisen from animal studies that have highlighted the corticopontine connections between the cerebral cortex and the cerebellum. In a series of studies conducted with rhesus monkeys, Schmahmann and Pandya (1997) showed that there are projections to pons from posterior parietal cortex, superior temporal gyrus, posterior parahippocampal areas, parastriate cortices, and prefrontal cortex. This observation suggests that the cerebellum has access to higher order information concerning social, emotional and cognitive behavior, which connect in parallel (Middleton \& Strick, 1997). These parallel routes are organized in a way that cerebellar regions receiving input from a given cortical area relay output back to the same cerebral area, thus forming parallel segregated circuits. Altogether, these studies strongly support the view that the cerebellum plays also a functional role in nonmotor cognition.

Surprisingly, to our knowledge, only two cognitive rehabilitation therapies of CCAS patients have been documented. Maeshima and Osawa (2007) described the case of a 61-year-old man who presented cerebellar hemorrhage in the areas of the vermis and developed a CCAS. Cognitive rehabilitation was focused on real orientation therapy and attention process training. The authors observed a general improvement of cognitive functioning, but significant memory, attention, and executive deficits remained. Schweizer et al. (2008) assessed the efficacy of a cognitive rehabilitation technique, Goal Management Training (GMT) (Robertson, 1996), in a 41-year-old patient with persisting executive dysfunction following a right cerebellar hemorrhage. Among other issues, the patient complained of slowed information processing and difficulties with daily planning, which resulted in an inability to return to work. After seven weekly two-hour sessions using the GMT technique, the authors observed modest but significant gains in areas specifically targeted by the rehabilitation. The benefits were maintained at the long-term follow-up and the patient could return to his demanding profession.

We report here the neuropsychological rehabilitation of a 16-year-old patient who presented a CCAS following a bilateral cerebellar hemorrhage. Murith et al. (2012) previously described the detailed physical presentation of this patient. The aim of the present case report is to 
show evidences on the effectiveness of articulated behavioral and cognitive training, as well as the usefulness to integrate this training in a vocational project. The rehabilitation process was divided into two distinct phases: a) a neurobehavioral approach in the sub-acute phase; and b) a therapy focused on specific cognitive deficits when the patient's clinical state improved.

\section{CLINICAL CASE}

The patient is a 16-year-old right-handed teenager who played sports and had no particular medical history or difficulties at school. In March 2011, after a soccer practice, he presented with an acute headache and progressive loss of consciousness. He was immediately brought to the emergency facility and a CT scan revealed a bilateral cerebellar hemorrhage, predominantly right (Figure 1a), on an arteriovenous malformation of the right superior cerebellar artery. He had a bilateral occipital craniotomy for hematoma evacuation and ventricular drainage on the same day. On the fifth day he benefitted from a selective embolization of the right superior cerebellar artery, then a ventroperitoneal shunt. Following different medical complications and neurological stabilization, the patient was rapidly transferred to a pediatric rehabilitation clinic.

Clinically, he first presented with severe and diffuse cognitive deficits, massive behavioral disorders (disinhibition, verbal, and physical aggressiveness, anosognosia), and emotion regulation difficulties (emotional indifference, social avoidance, and hypomimia) associated with fluctuating consciousness, oculomotor disorders, dysarthria, mild tetraparesis, and significant ataxia of the trunk and limbs. During the nine months in the rehabilitation clinic, the patient presented several health complications (aspiration pneumonia, hydrocephalus, and ventriculitis in relation to the shunt) and no significant clinical improvement was observed.

In December 2011, the patient was transferred to our rehabilitation center, closer to his family and friends. The Functional Independence Measure at entry was 37/126. After two months in the second rehabilitation center, clinical examination showed no significant improvement, with persistence of severe motor, cognitive, emotional, and behavioral disorders. In particular, clinical examination showed multidirectional nystagmus and bilateral limb ataxia. A neuropsychological examination revealed severe deficits in attention (sustained and divided attention, processing speed) and executive functions (shifting, cognitive inhibition and sequencing), associated with mild deficits in verbal and visuospatial anterograde memory, mental arithmetic, and language (word finding, paraphasias) (Table 1). Control neuroimaging confirmed a bilateral global cerebellar posthemorrhagic sub-cortical atrophy, mostly subcortical, predominating right, including the posterior part of the vermis and hemispheres but also the right flocculus (Figure 1b).

(a)

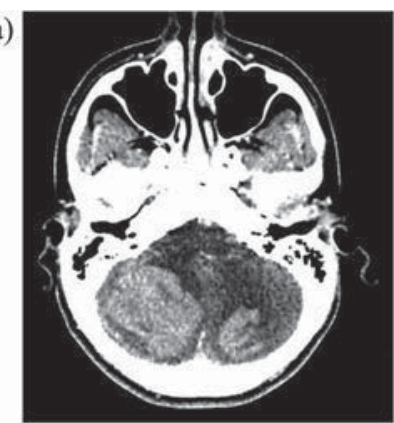

(b)

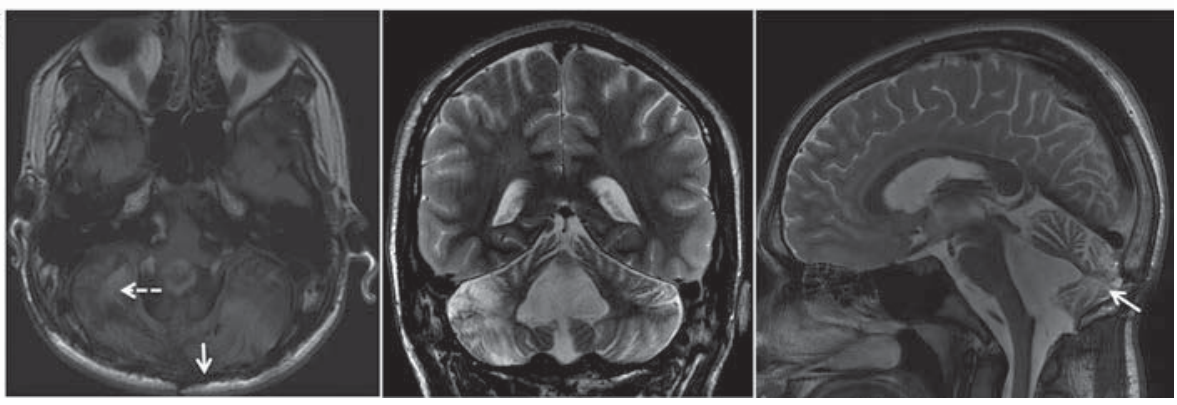

FIGURE 1 (a) Initial CT-scan showing a bilateral cerebellar hemorrhage (right is on the left side). Figure 1(b) MRI of the chronic cerebellar lesion, 1 year after hemorrage and embolization. Neuroimaging (right is on the left side) shows a bilateral global subcortical cerebellar atrophy, more on the right, where it includes anterior floccular structures (see white dashed arrow). Note the dilatation of the 4th ventricle and the involvement of posterior vermis (see white arrows), while anterior-superior part of the vermis is spared. 
TABLE 1

Cognitive Performances at the Three Neuropsychological Assessments. Neurobehavioral Intervention was Performed between First and Second Assessment (Dotted Line)

Praxis

Gnosia

Memory

Executive functions
Temporal orientation

Spatial orientation

Speech (dysarthria)

Semantic Verbal Fluency

Number of words

Phonetic Verbal Fluency

Number of words

Boston Naming Test

Denomination $(/ 34)$

Stroop (Stroop, 1935)

Reading condition (time in seconds)

Naming condition (time in seconds)

Writing (cerebellar dysgraphia)

Calculation

Mental

Written

Ideomotor praxia (/23)

Constructive praxia

Figure copy

Discriminative gnosia

Associative gnosia

Columbia test $(/ 12)$

Auditivo-verbal short-term memory (Hebb, 1949)

Span

Visuo-spatial short-term memory (Corsi, 1972)

Span

Verbal anterograde memory 10 words

(Rey's 10 words)

Total items learned 1-3 trials

Recognition $(/ 10)$

Long-term Delay (/10)

Verbal anterograde memory 15 words

(Rey's 15 words, Rey, 1970)

Total items learned 1-5 trials

Recognition (/15)

Long-term Delay (/15)

Verbal anterograde memory CVLT (Delis, 2000)

Total items learned 1-5 trials

Recognition (/15)

Long-term Delay (/15)

Visual anterograde memory (Rey's 15 signs)

Total items learned 1-5 trials

Recognition (/15)

Long-term Delay $(/ 15)$

DMS 48 (Barbeau, et al., 2004)

Set 1 (immediate recognition)

Set 2 (long term recognition)

1 st assessment 2nd assessment $3 r d$ assessment (03.01.2012)

(19.04.2012

(18.04.2013)

$* * *$

$\mathrm{N}$
$* *$

$\mathrm{N}$

$\begin{array}{cc}* * & \mathrm{~N} \\ \mathrm{~N} & \mathrm{~N}\end{array}$

$18 \mathrm{~N}$

$30 \mathrm{~N}$

$5^{*}$

$14 \mathrm{~N}$

$23^{* *}$

$28 \mathrm{~N}$

$28 \mathrm{~N}$

$61^{* * * *}$

$64^{* * * *}$

$24 \mathrm{~N}$

$31 \mathrm{~N}$

$22 \mathrm{~N}$

$23 \mathrm{~N}$

Simple figure* Cube N

$\mathrm{N}$

$11 \mathrm{~N}$

$5^{*}$

$7 \mathrm{~N}$

$7 \mathrm{~N}$

$6 \mathrm{~N}$

$7 \mathrm{~N}$

$22^{* * *}$

$8 * *$

$3^{* * *}$

$15 \mathrm{~N}$

$12 \mathrm{~N}$

$43^{*}$

$46^{*}$

$14 \mathrm{~N}$

$10^{* *}$

Rey's complex figure Copy

Copy without programming

Copy with programming

Long-term delay recall

Wisconsin Card Sorting Test (Grant \& Berg,1948)

Luria's design sequences

Number of sequences (time in seconds)

Figural fluency (5 points, Regard, Strauss, \& Knapp, 1982)

Number of productions

Stroop Test (Stroop, 1935)

$\begin{array}{cc} & 47 \mathrm{~N} \\ & 46^{* *} \\ & \\ 22.5^{* * *} & 28^{* *} \\ 36 \mathrm{~N} & 36 \mathrm{~N} \\ 7.5^{*} & 9.5^{*} \\ 2 \mathrm{~N} & 3 \mathrm{~N} \\ 7(44)^{*} & 9(41)^{*} \\ & \\ 25 \mathrm{~N} & 31 \mathrm{~N}\end{array}$




\begin{tabular}{|c|c|c|c|c|}
\hline & & $\begin{array}{l}\text { 1st assessment } \\
(03.01 .2012)\end{array}$ & $\begin{array}{l}\text { 2nd assessment } \\
(19.04 .2012)\end{array}$ & $\begin{array}{c}3 r d \text { assessment } \\
(18.04 .2013)\end{array}$ \\
\hline & Stroop condition (time in seconds) & *** & $42 \mathrm{~N}$ & $39 \mathrm{~N}$ \\
\hline & TMT A (Reitan, 1958) & & & \\
\hline & Time in seconds & & $53^{* * *}$ & $37 \mathrm{~N}$ \\
\hline & TMT B (Reitan, 1958) & & & \\
\hline & Time in seconds & & $193^{* * *}$ & $111 \mathrm{~N}$ \\
\hline & Behavioral Assessment of the Dysexecutive & & & \\
\hline & Syndrome (Norris, 2000) & & $\mathrm{N}$ & \\
\hline \multirow[t]{2}{*}{ Social cognition } & Faux-pas (/78) (Stone, Baron-Cohen, \& Knight, 1998) & & $72 \mathrm{~N}$ & \\
\hline & Reading the Mind in the Eyes Test (/26) (Baron-Cohen, et al., 2001) & & $20^{*}$ & $23 \mathrm{~N}$ \\
\hline \multirow[t]{11}{*}{ Attention } & D2 (Brickenkamp, 1969) & & & \\
\hline & GZ (efficiency) & & $284^{* * *}$ & $417 \mathrm{~N}$ \\
\hline & $\mathrm{F} \%(\%$ of error) & & $5 \mathrm{~N}$ & $6 \mathrm{~N}$ \\
\hline & Test of Attentional Performance-Alertness (Zimmermann, 1995) & & & \\
\hline & Without backup alarm (time in seconds) & & $340^{* *}$ & $296 \mathrm{~N}$ \\
\hline & With backup alarm (time in seconds) & & $325^{* *}$ & $299^{*}$ \\
\hline & Test of Attentional Performance & & & \\
\hline & Divided Attention (Zimmermann, 1995) & & & \\
\hline & Auditive condition & & $480 \mathrm{~N}$ & $480 \mathrm{~N}$ \\
\hline & Visual condition & & $793 \mathrm{~N}$ & $795 \mathrm{~N}$ \\
\hline & Omission + errors & & $5^{* *}$ & $5^{* *}$ \\
\hline \multirow[t]{3}{*}{ Hand dexterity } & Purdue Pegboard (Tiffin, 1968) & & & \\
\hline & Dominant Hand (total 1-3 trials) & & $17^{* * *}$ & $21^{* * *}$ \\
\hline & Non Dominant Hand (total 1-3 trials) & & $21^{* * *}$ & $27^{* * *}$ \\
\hline \multirow{7}{*}{$\begin{array}{l}\text { General intellectual } \\
\text { functioning }\end{array}$} & WISC-IV (Wechsler, 2005) & & & \\
\hline & Full Scale Intellectual Quotient & & $83 \mathrm{~N}$ & \\
\hline & Verbal Comprehension Index & & $99 \mathrm{~N}$ & \\
\hline & Perceptual Reasoning Index & & $82 \mathrm{~N}$ & \\
\hline & Working Memory Index & & $103 \mathrm{~N}$ & \\
\hline & Processing Speed Index & & $66^{* * *}$ & $69^{* * *}$ \\
\hline & Raven's Progressive Matrices (/30)(Raven, 1990) & & & $20 \mathrm{~N}$ \\
\hline $\begin{array}{l}\text { Functional Independence } \\
\text { Measure }\end{array}$ & MIF scale (/126) (Hamilton, 1987) & 37 & 124 & \\
\hline
\end{tabular}

CVLT $=$ California Verbal Learning Test DMS $=$ Delayed Matching to Sample; TMT $=$ Trail Making Test.

$\mathrm{N}=$ performance within normal range; ${ }^{*}$ mild deficit; ${ }^{* *}$ moderate deficit; ${ }^{* * *}$ severe deficit.

\section{NEUROBEHAVIORAL INTERVENTION}

At that point his behavioral disorders were so severe that no therapy could be continued, and several psychopharmacotherapy trials were ineffective (neuroleptics, methylphenidate, benzodiazepines, and antidepressants). The rehabilitation was therefore oriented toward regulation of the conduct disorders and a rigorous transdisciplinary behavioral approach was set up in two steps. During the first phase (lasting two weeks) the medical team wrote down on a descriptive table the patient's main problematic behaviors, circumstances, consequences, and their frequency (examples reported in Table 2). Nine different problematic behaviors were reported by the medical team, three of which were selected to be targeted during the second stage.

In the second phase, an emulation board based on the three targeted behaviors was introduced into the patient's room. The objective of the patient was to move a pawn forward on the board in order to receive a reward he had previously chosen. The pawn could be advanced after a satisfactory action (in reference to the targeted behaviors). For example, if the patient participated in a complete therapy session, the pawn was moved one stage forward. The pawn represented his favorite soccer player, who progressed on a soccer field in order to score a goal. After a given number of pawn progressions (30), the player scored the goal leading to a reward previously chosen by the patient. The instructions were written next to the board.

The patient quickly took to the emulation board; after only a few days, he would remind the caregivers to move the pawn when he had respected the criteria and, at the end of the first week, he moved the player on the board by himself. Therapists noted the progression on a separate board, as the patient tried once to "cheat" in the absence of therapists. Whenever a problematic behavior was not observed for a week, it was replaced by another problematic behavior to be targeted. Six weeks after the introduction of the board, the patient had completed the course three times and had received three different rewards. After the third reward, he asked the therapists 
TABLE 2

Examples of Problematic Behaviors Reported by the Medical Team, with the Description of the Circumstances, Consequences, and Frequency

\begin{tabular}{|c|c|c|c|}
\hline Problematic behaviors & Circumstances & Consequences & Frequency \\
\hline Verbal aggressiveness & Blood test, with nursing staff & $\begin{array}{l}\text { Patient refuses blood test, becomes aggressive and insults } \\
\text { nursing staff }\end{array}$ & $\begin{array}{r}2 \mathrm{x} \text { this } \\
\text { week }\end{array}$ \\
\hline Urine incontinence & Right after his friends' visit & Patient withdraws into himself, then refuses all therapies & $\begin{array}{r}3 \mathrm{x} \text { this } \\
\text { week }\end{array}$ \\
\hline $\begin{array}{l}\text { Going to other patients' } \\
\text { rooms }\end{array}$ & During the night & Intervention of the nurse, patient returns calmly to his room & $\begin{array}{l}1 \mathrm{x} \text { this } \\
\text { week }\end{array}$ \\
\hline Refusing to take a shower & $\begin{array}{l}\text { In the morning, after breakfast, with } \\
\text { nursing staff }\end{array}$ & $\begin{array}{l}\text { Patient withdraws into himself, refuses visitors because of his } \\
\text { bad hygiene }\end{array}$ & $\begin{array}{r}2 \mathrm{x} \text { this } \\
\text { week }\end{array}$ \\
\hline
\end{tabular}

to remove the board as he felt it was no longer necessary. By the time the patient asked for the board to be removed he was actively participating in all therapy sessions. Simultaneously, a significant reduction in the frequency of the problematic behaviors was observed.

Therefore, the frequency and duration of the neuropsychological therapies were progressively increased to daily sessions of 45 minutes. The cognitive rehabilitation was then focused on five specific domains:

1. Executive functions (shifting, cognitive inhibition, planning), with verbal fluency exercises, card shifting games, visual story sequencing, research and planning exercises on the internet (for example: elaborating a plan with different costs and timelines to organize a trip to a foreign country with his family), and computer rehabilitation tasks.

2. Sustained and divided attention, processing speed: computerized tasks and paper-pencil exercises.

3. Anterograde memory: face-name learning of the therapists, summarizing of text read, paper-pencil exercises to perform in his room and to return to every day (i.e., "homework").

4. Mental arithmetic: computer tasks and counting exercises.

5. Speech therapy (dysarthria): increasing tongue movement speed, breathing coordination exercises, singing exercises to modify his monotonous voice, articulation tasks (reading and repetition of complex material).

Grapho-Motor improvement was carried out by the occupational therapists. In April 2012, after two months of intensive cognitive rehabilitation (44 sessions), we observed a significant improvement in executive function, attention, memory, mental processing speed, and mental arithmetic. Global intellectual functioning, assessed with the WISC-IV (Wechsler, 2005), showed a Full Scale Intellectual Quotient in the low average (FSIQ: 83). The Processing Speed Index was notably lower (PSI: 66) than the other indexes (Verbal Comprehension Index: 99,
Perceptual Reasoning Index: 82, Working Memory Index: 103). This advance was also observable in activities of daily living, as he was, for example, able to manage his daily planning and come promptly to therapy sessions.

However, mild to moderate cognitive difficulties remained in the following domains: verbal and visuospatial memory, executive functions, attention (processing speed, sustained and divided attention), visuospatial organization and hand dexterity. A nine-month period of amnesia persisted after the hemorrhage. Graphomotor speed very much improved but did not reach normal performance and discrete cerebellar dysarthria persisted. On the behavioral side, occasional nightly incontinence was still present and a slight personality change remained, with light disinhibition (for example, inadequate use of humor, giving surnames to therapists, etc.), apathy and emotional blunting. On the motor side, the patient achieved major improvements in motor coordination, an independent gait being possible (although the ataxic walk remained).

While the patient was still at hospital, a specialized teacher came twice weekly and he could then progressively go back to school. Initially, his professors reported some behavioral problems, the patient being passive and tending to disturb the class. Disturbing the class rapidly regressed, but the lack of initiative remained. The patient progressively became almost independent in all activities of daily living. Home adaptations were made with occupational therapists and the patient was discharged home in June 2012, 15 months after the CVA. The Functional Independence Measure at discharge was $124 / 126$ (vs 37/126 at entry).

A further neuropsychological assessment was performed two years after the cerebellar hemorrhage (one year after the home discharge) (see Table 1). This evaluation showed an overall cognitive improvement compared to the assessment performed before discharge, but the cognitive profile remained the same. Despite the mild cognitive and behavioral sequelae, he could complete his schooling and started an apprenticeship adapted to his difficulties. 


\section{DISCUSSION}

We report the case of a 16-year-old patient who was initially presented with a severe CCAS following a bilateral cerebellar hemorrhage. The patient showed no significant clinical improvement for one year, and then rapidly made cognitive and motor progress after behavioral and environmental intervention. This case illustrates how behavioral disorders can mask great rehabilitation potential. In accordance with the dysmetria of thought hypothesis (Schmahmann \& Sherman, 1998) the patient had major difficulties in self-regulating his thoughts and behavior. We suggest that the introduction of a rigorous transdisciplinary neurobehavioral approach helped him regain control over himself, acting in a certain manner as an "external cerebellum."

Following the introduction of the emulation board, a rapid behavioral improvement was observed. The use of an emulation board allowed the patient to actively participate in his rehabilitation and to see his progression concretely, as he had major difficulties internalizing the therapists' feedback. The system was a positive reinforcement only, as the pawn would never move back on the board after a negative behavior. We chose to avoid negative reinforcement because of the patient's emotional regulation difficulties, which could have led to a rejection of the board. We observed that the patient was mainly interested in the progression of the pawn, and not so much in the reward as such. The attempt of the patient to "cheat" was interpreted as a positive sign of his involvement in the system. The fact that he asked spontaneously to have the board withdrawn was also very interesting, as it suggested the patient felt he had regained enough self-control by that time.

Indeed, Schmahmann (2010) states "an important feature that differentiates cerebellar cognition from disorders of cerebral cortex is that the cerebellar lesion can be compensated for, at least in part, by bringing the issue at hand to conscious awareness, focusing on the problem in order to address it" (p. 254). We believe this is precisely what the emulation board helped the patient do. In addition, it gave the patient a motivational reference that he could use.

The inclusion of the patient in the process of developing the emulation board was essential as it allowed him to appropriate the system and probably facilitated its acceptance. The system was first explained to the patient. We then proposed using a soccer field, and he chose his favorite player to be the pawn. As behavioral disorders were still dominant he could not entirely construct the board with the occupational therapist, but he participated in painting some parts of the field. Such an approach has been used in adolescents after traumatic brain injuries (Slifer \& Amari, 2009), but, to our knowledge, this is the first description of such a therapy following a cerebellar lesion.

We should acknowledge several caveats regarding this study. Primarily, as we describe the neuropsychological rehabilitation of an uncontrolled single case, our findings cannot be directly generalized to other similar clinical cases. This cautiousness in proposing generalization is also due to the heterogeneity of the clinical pictures in CCAS. Secondly, it cannot be stated that the introduction of the emulation system exclusively explained the rapid regression of the behavioral disorders as several other factors may have contributed. The patient had been transferred two months earlier to our rehabilitation center which is located in his native town, closer to his family and friends. This probably contributed to a global spatial and affective restoration. Additionally, spontaneous recovery cannot be evaluated, even though the patient was probably in the chronic phase of recovery at the time of the intervention as no significant clinical improvement had been observed for a year. Finally, this rehabilitation has been articulated with a "return to school" project, which offered a medium term goal as motivational drive. This aim has probably played a significant role in patients' adherence to therapy. From our point of view, the emulation system created a trigger effect in the rehabilitation process, which opened the way to progress in motor and cognitive functions.

As Schmahmann (2010) points out, there is no empirical evidence that pharmacological approaches to managing alterations in mood and behavior are effective in this population. Therefore, cognitive intervention in managing the behavioral deficits was critical. The pluridisciplinary approach was also essential, as all the caregivers needed to be similarly focused to allow the patient to have a steady point of reference to which to adapt his behavior. The patient's family and friends were also implicated in the rehabilitation process.

Furthermore, this clinical case shows the importance of long-term and intensive neurorehabilitation. In this CCAS case, major clinical improvement occurred over one year after the hemorrhage. Wingeier et al. (2011) studied the long-term sequelae after acquired pediatric hemorrhagic cerebellar lesions among eight children under the age of 13 . The assessments were done at least 12 months post-injury. Although all patients exhibited motor problems and neuropsychological impairments in laboratory conditions, they reported having a good quality of life without any major physical restrictions. Cognitive impairments were mild, with very heterogeneous profiles; reduced reaction times and susceptibility to interference were the most frequent symptoms. According to the authors, these findings support the idea that acute symptoms can be observed in cerebellar hemorrhagic lesions, but have a promising long-term prognosis and good quality of life. Negative outcome predictors were a 
young age at the time of injury and bihemispheric cerebellar lesions, and CCAS syndrome was only observed among patients with vermis lesions.

Even though the clinical evolution of this case was positive in the long term, mild cognitive and behavioral deficits remained. In particular, the reduction of his information processing speed did not improve over time, contrary to the other cognitive functions. The role of the cerebellum in mental processing speed has been suggested earlier by Botez' work (Botez-Marquard, Leveille, \& Botez, 1994; Botez, 1993) and further by Schmahmann (2010), who also considers that the cerebellum is crucial in regulating the speed of cognitive processes. Besides, mild executive dysfunction also remained. This is congruent with the primary observation of Schmahmann and Sherman (1998), who found that after cerebellar lesions initial cognitive deficits improved over time, with the exception of executive function, which remained below the mean (patients were tested one to nine months after the onset). The executive deficits probably account for the mild difficulties observed in anterograde memory, as the patient's pattern of performance on the word list indicated a reduction in the executive control of memory (many intrusions and perseverations, sensibility to interference, lack of strategy). As he was presenting with emotional bluntness, his social cognition was investigated. Two tasks were administered and showed no particular difficulty (Table 1): Reading in the Eyes Test (Baron-Cohen, Wheelwright, Hill, Raste, \& Plumb, 2001) and Faux Pas Recognition Test (Baron-Cohen, O’Riordan, Stone, Jones, \& Plaisted, 1999).

As already mentioned, very few cognitive rehabilitation therapies of CCAS patients have been reported. Relevant to our clinical case, Schweizer et al. (2008) report long-term cognitive benefits using Goal Management Training (Robertson, 1996) in a 41-year-old patient with persisting executive dysfunction following a right cerebellar hemorrhage. Considering the executive deficits which persist in our patient, this rehabilitation technique might be useful, as he has just started an apprenticeship and will face learning challenges where the application of Goal Management Training might be of great help.

On the motor side, after suffering cerebellar lesions, patients usually improve their mobility in up to three to eight months after the event (Someya, Tachino, \& Kagechika, 1997). In this case, although important trunk and limbs ataxia was present, major improvement in mobility started 10 months after the hemorrhage, with an independent gait being possible about 15 months after the hemorrhage (although the ataxic walk remained). Several hypotheses may explain the spectacular motor improvement in this patient: his young age at the onset of the cerebral lesions, natural predisposition, and concomitance of rapid cognitive evolution. Cognitive and physical improvement may be influenced in both ways; according to Schmahmann (2010), cerebellar exercises (i.e., physical maneuvers that tap cerebellar motor control) may be effective in relieving other potential manifestations of cerebellar dysfunction (i.e., cognitive functions).

In conclusion, the neuropsychological rehabilitation of this CCAS patient provides two main indications: first, major clinical improvement can occur more than one year after the onset of the CCAS, showing the importance of long-term and intensive neurorehabilitation; second, neuropsychological intervention through a behavioral and cognitive approach was one of the decisive factors. More precisely, when the cerebellum cannot properly play its regulator role in cognition, the behavioral approach can be of great help by acting as an external modulator to help the patient regain control over himself. This hypothesis remains to be confirmed by subsequent clinical cases.

\section{ACKNOWLEDGMENTS}

The authors would like to thank the patient and his family for participating in this research. Informed consent was signed by the patient (patient was at age of majority at time of article publication).

\section{CONFLICT OF INTEREST}

None of the authors has a possible conflict of interest, financial or otherwise.

\section{REFERENCES}

Baillieux, H., De Smet, H. J., Paquier, P. F., De Deyn, P. P., \& Marien, P. (2008). Cerebellar neurocognition: Insights into the bottom of the brain, Clinical Neurology and Neurosurgery, 110, 763-773. doi:10.1016/j.clineuro.2008.05.013

Barbeau, E., Didic, M., Tramoni, E., Felician, O., Joubert, S., Sontheimer, A., Ceccaldi, M., \& Poncet, M. (2004). Evaluation of visual recognition memory in MCI patients, Neurology, 62, 1317-1322. doi:10.1212/01.wnl.0000120548.24298.db

Baron-Cohen, S., O’Riordan, M., Stone, V., Jones, R., \& Plaisted, K. (1999). Recognition of faux pas by normally developing children and children with Asperger syndrome or high-functioning autism, Journal of Autism and Childhood Schizophrenia, 29, 407-418.

Baron-Cohen, S., Wheelwright, S., Hill, J., Raste, Y., \& Plumb, I. (2001). The "Reading the Mind in the Eyes" Test revised version: a study with normal adults, and adults with Asperger syndrome or high-functioning autism, Journal of Child Psychology and Psychiatry, 42, 241-251. doi:10.1111/1469-7610.00715

Bellebaum, C., \& Daum, I. (2007). Cerebellar involvement in executive control. Cerebellum (London, England), 6(3), 184-192. doi:10.1080/ 14734220601169707 
Botez-Marquard, T., Leveille, J., \& Botez, M. I. (1994). Neuropsychological functioning in unilateral cerebellar damage, Canadian Journal of Neurological Sciences, 21, 353-357.

Botez, M. I. (1993). Cerebellar cognition, Neurology, 43, 2153-2154.

Botez, M. I., Gravel, J., Attig, E., \& Vezina, J. L. (1985). Reversible chronic cerebellar ataxia after phenytoin intoxication: Possible role of cerebellum in cognitive thought, Neurology, 35, 1152-1157. doi:10.1212/wnl.35.8.1152

Brickenkamp, R. (1969). Manuel du test D2. Bruxelles, Belgium: Editest.

Chiricozzi, F. R., Clausi, S., Molinari, M., \& Leggio, M. G. (2008). Phonological short-term store impairment after cerebellar lesion: A single case study. Neuropsychologia, 46(7), 1940-1953. doi:10.1016/j.neuropsychologia.2008.01.024

Corsi, P. M. (1972). Human memory and the medial temporal region of the brain. Dissertation Abstracts International, 34(2), 891B. (University Microfilms No. AAI05-77717).

Delis, D. C., Kramer, J. H., Kaplan, E., \& Ober, B. A. (2000). California verbal learning test (2nd ed.). San Antonio, TX: Psychological Corporation.

Gottwald, B., Mihajlovic, Z., Wilde, B., \& Mehdorn, H. M. (2003). Does the cerebellum contribute to specific aspects of attention? Neuropsychologia, 41(11), 1452-1460. doi:10.1016/s0028-3932(03) 00090-3

Gottwald, B., Wilde, B., Mihajlovic, Z., \& Mehdorn, H. M. (2004). Evidence for distinct cognitive deficits after focal cerebellar lesions. Journal of Neurology, Neurosurgery, and Psychiatry, 75(11), 1524-1531. doi:10.1136/jnnp.2003.018093

Grant, D. A., \& Berg, E. A. (1948). A behavioral analysis of degree of reinforcement and ease of shifting to new responses in a Weigl-type card-sorting problem, Journal of Experimental Psychology, 38, 404-411. doi:10.1037/h0059831

Grasby, P. M., Frith, C. D., Friston, K. J., Bench, C., Frackowiak, R. S. J., \& Dolan, R. J. (1993). Functional mapping of brain areas implicated in auditory-verbal memory function, Brain, 116, 1-20.

Hebb, D. O. (1949). The organization of Behavior. A Neuropsychological theory. New York, NY: Wiley.

Holmes, G. (1939). The cerebellum of man. Brain, 1-30. doi:10.1093/ brain/62.1.1

Keith, R. A., Granger, C. V., Hamilton, B. B., \& Fielder, R. C. (1987). The functional independence measure: A new tool for rehabilitation. In M. G. Eisenberg, \& R. C.Grzesiak (Eds), Advances in Clinical Rehabilitation, pp. 6-18. New York, NY: Springer-Verlag.

Klein, D., Milner, B., Zatorre, R. J., Meyer, E., \& Evans, A. C. (1995). The neural substrates underlying word generation: A bilingual functional-imaging study, Proceedings of the National Academy of Sciences of the United States of America, 92, 2899-2903. doi:10.1073/pnas.92.7.2899

Leggio, M. G., Tedesco, A. M., Chiricozzi, F. R., Clausi, S., Orsini, A., \& Molinari, M. (2008). Cognitive sequencing impairment in patients with focal or atrophic cerebellar damage. Brain, 131(5), 1332-1343. doi:10.1093/brain/awn040

Leiner, H. C., Leiner, A. L., \& Dow, R. S. (1986). Does the cerebellum contribute to mental skills?, Behavioral Neuroscience, 100, 443-454. doi:10.1037//0735-7044.100.4.443

Maeshima, S., \& Osawa, A. (2007). Stroke rehabilitation in a patient with cerebellar cognitive affective syndrome, Brain Injury, 21, 877-883.

Middleton, F. A., \& Strick, P. L. (1997). Dentate output channels: Motor and cognitive components, Progress in Brain Research, $114,553-566$

Molinari, M., Petrosini, L., Misciagna, S., \& Leggio, M. G. (2004). Visuospatial abilities in cerebellar disorders. Journal of Neurology, Neurosurgery, and Psychiatry, 75(2), 235-240.
Murith, C., Colombo, F., Ruffieux, N., Zappalac, A., Teichler, J., Haller, M., ... Bihl, T. (2012). Rôle non moteur du cervelet: «dysmétrie» comportementale induite par lésion cérébelleuse?, Revue Médicale Suisse, 12, 897-898.

Neau, J. P., Arroyo-Anllo, E., Bonnaud, V., Ingrand, P., \& Gil, R. (2000). Neuropsychological disturbances in cerebellar infarcts. Acto Neurologica Scandinavica, 102(6), 363-370. doi:10.1034/j.16000404.2000.102006363.x

Norris, G. T., \& R. L. Tate. (2000). The behavioural assessment of the dysexecutive syndrome (BADS): Ecological, concurrent and construct validity. Neuropsychological Rehabilitation, 10(1), 33-45. doi:10.1080/096020100389282

Peterburs, J., Bellebaum, C., Koch, B., Schwarz, M., \& Daum, I. (2010). Working memory and verbal fluency deficits following cerebellar lesions: Relation to interindividual differences in patient variables. Cerebellum, 9(3), 375-383. doi:10.1007/s12311010-0171-z

Raven, J. C., Raven, J. C., \& De Lemos, M. M. (1990). Standard progressive matrices. Oxford, UK: Oxford Psychologists Press.

Regard, M., Strauss, E., \& Knapp, P. (1982). Children's production on verbal and non-verbal fluency tasks, Perceptual and Motor Skills, 55, 839-844. doi:10.2466/pms.1982.55.3.839

Reitan, R. M. (1958). Validity of the Trail Making test as an indicator of organic brain damage. Perceptual and Motor Skills, 8, 271-276. doi:10.2466/pms.8.7.271-276

Rey, A. (1970). L'examen clinique en psychologie. Paris, France: PUF.

Richter, S., Schoch, B., Kaiser, O., Groetschel, H., Dimitrova, A., Hein-Kropp, C., ... Timmann, D. (2005). Behavioral and affective changes in children and adolescents with chronic cerebellar lesions. Neuroscience Letters, 381(1-2), 102-107. doi:10.1016/j.neulet. 2005.02.011

Robertson, I. H. (1996). Goal management training: A clinical manual. Cambridge, UK: PsyConsult.

Schmahmann, J. D. (1991). An emerging concept. The cerebellar contribution to higher function, Archives of Neurology, 48, 11781187. doi:10.1001/archneur.1991.00530230086029

Schmahmann, J. D. (2010). The role of the cerebellum in cognition and emotion: personal reflections since 1982 on the dysmetria of thought hypothesis, and its historical evolution from theory to therapy, Neuropsychology Review, 20, 236-260. doi:10.1007/s11065010-9142-x

Schmahmann, J. D., \& Pandya, D. N. (1997). Anatomic organization of the basilar pontine projections from prefrontal cortices in rhesus monkey. The Journal of Neuroscience: The Official Journal of the Society for Neuroscience, 17(1), 438-458.

Schmahmann, J. D., \& Sherman, J. C. (1998). The cerebellar cognitive affective syndrome. Brain, 121(Pt 4), 561-579. doi:10.1093/brain/ 121.4.561

Schweizer, T. A., Levine, B., Rewilak, D., O’Connor, C., Turner, G., Alexander, M. P., ... Stuss, D. T. (2008). Rehabilitation of executive functioning after focal damage to the cerebellum, Neurorehabilitation and Neural Repair, 22, 72-77.

Shin, J. C., \& Ivry, R. B. (2003). Spatial and temporal sequence learning in patients with Parkinson's disease or cerebellar lesions. Journal of Cognitive Neuroscience, 15(8), 1232-1243. doi:10.1162/ 089892903322598175

Slifer, K. J., \& Amari, A. (2009). Behavior management for children and adolescents with acquired brain injury, Developmental Disabilities Research Reviews, 15, 144-151. doi:10.1002/ddrr.60

Someya, F., Tachino, K., \& Kagechika, K. (1997). Evaluation for physical recovery of patients with cerebellar stroke. Sogo Rehabilitation (Tokyo) 25, 743-747. 
Spurzheim, J. C. (1815). The physiognomical system of Drs. Gall and Spurzheim. London, England: Orson.

Stone, V. E., Baron-Cohen, S., \& Knight, R. T. (1998). Frontal lobe contributions to theory of mind, $J$ Cogn Neurosci, 10, 640-656. doi:10.1162/089892998562942

Stoodley, C. J. (2012). The cerebellum and cognition: Evidence from functional imaging studies, Cerebellum, 11, 352-365. doi:10.1007/ s12311-011-0260-7

Stroop, J. (1935). Studies of interference in serial verbal reactions. Journal of Experimental Psychology, 18, 643-662. doi:10.1037/ h0054651

Tedesco, A. M., Chiricozzi, F. R., Clausi, S., Lupo, M., Molinari, M., \& Leggio, M. G. (2011). The cerebellar cognitive profile. Brain, 134(12), 3669-3683.
Tiffin, J. (1968). Purdue pegboard: Examiner manual. Chicago, IL: Science Research Associates.

Turner, B. M., Paradiso, S., Marvel, C. L., Pierson, R., Boles Ponto, L. L., Hichwa, R. D., \& Robinson, R. G. (2007). The cerebellum and emotional experience. Neuropsychologia, 45(6), 1331-1341. doi:10.1016/j.neuropsychologia.2006.09.023

Wechsler, D. (2005). The Wechsler Intelligence Scale for Children, (4th ed.). (WISC-IV). Paris, France: ECPA.

Wingeier, K., Bigi, S., El-Koussy, M., Heinks-Maldonado, T., Boltshauser, E., \& Steinlin, M. (2011). Long-term sequelae after acquired pediatric hemorrhagic cerebellar lesions, Childs Nervous System, 27, 923-931. doi:10.1007/s00381-010-1357-x

Zimmermann, P. a. F., B. (1995). Test for Attention Performance $(T A P)$. Würselen, Germany: Psytest. 